\title{
Nurses' Knowledge, Attitude and Practice Towards Preparedness of Disaster Management in Emergency of Mosul Teaching Hospitals
}

\author{
Nasir M. Younis ${ }^{1}$, Mahmoud M. Ahmed ${ }^{2}$, Ahmed A. Hussein ${ }^{2}$ \\ ${ }^{1}$ Assist.Prof, MScN. CH.N, University of Mosul/ College of Nursing. Iraq, ${ }^{2}$ Instructor, MScN. CH.N, University of \\ Mosul/College of Nursing. Iraq, ${ }^{3}$ Instructo, MScN. CH.N, University of Mosul/College of Nursing. Iraq
}

\begin{abstract}
Background: Disasters define as event everywhere in the world every day and have a significant impact on individuals, families, group and communities.

Objectives: The aim of the study was to assessment the nurses' knowledge, attitude and practice about preparedness of disaster management in emergency of Mosul teaching hospitals/Iraq

Materials and Method: In a cross-sectional analysis. The questionnaire consists of (4) main sections: section one demographic date e.g: (age, sex, experience, education level, marital status, and hospitals). Section two included: (47) items related to level of knowledge among nurses about disaster preparedness. Section three consists of (11) elements concern attitude about disaster management. Section four related to practice of regarding disaster management.
\end{abstract}

Results: indicated the finding of the study nurses' knowledge, attitude and practice about preparedness of disaster management in emergency department of Mosul teaching hospitals are highly significant.

Conclusion: Through the findings of the study concluded that the awareness or knowledge of nurses is high with a neutral level of attitude, also practice with respect to disaster preparedness was satisfactory.

Keywords: Knowledge, Attitude, practice, Disaster Management.

\section{Introduction}

Disaster is the main functional degradation or loss of resources such as life, economy and buildings (1). Disasters event everywhere in the world and have influence on people, families, group and communities (2) . The first decade of the 21century had increased consciousness of the possible danger posed by disasters, both natural and manmade, to modern society (3). Disasters can be categorized to natural and manmade natural disasters occur from natural causes which include volcanic eruptions, hurricanes, burning, which

\section{Corresponding Author:}

Nasir M. Younis

E-mail: nasir_younse@yahoo.com tornadoes. Infectious catastrophes may also be marked as pandemic ${ }^{(4)}$.While (Hassmiller and Stanley, 2013) stated the disasters can be three categorized group included: natural disasters such as floods, droughts, earthquakes, disease epidemics, technical incidents such as fires, structural failure, radiological accidents, civil / political events such as attacks, terrorism and biological warfare ${ }^{(5)}$. Approximately $48 \%$ of all disasters occurred in 2014 in asia had an area that was largely disaster-induced, reporting that (90.13percent) of worldwide disasters came through asia ${ }^{(6)}$. In $\operatorname{Iraq}^{(7)}$ , an epidemiological study between years (2008-2012) indicate that the highest death rate due to disasters, including terrorism, was in 2008 due to sectarian conditions at a rate of $(24.36 \%)$. Disaster preparedness, risk assessment and multidisciplinary management of all levels of the system, is essential to providing 
successful solutions to a disaster stricken population's short and long term health needs ${ }^{(8)}$. The World Health Organization has recommended that all countries must be prepared for crisis they face crisis and most nurses have ineffectively trained for disasters ${ }^{(9)}$. The recovery mechanism is structured to handle disasters and help those who are at risk of catastrophe and recover after the crisis has been caught up to allow the individuals who have been impact to benefit from the catastrophe (6). Nurses 'role in and recovery of disaster management includes emergency preparedness, prevention, response and recovery from emergencies and after disasters ${ }^{(10)}$ In Iraq the last fifteen years the frequency of disasters has increased, especially terrorism and traffic accidents. The aim of the study to assess of KAP of nurses' in disasters management at teaching hospitals in Mosul City.

\section{Methodology}

This study employed a questionnaire to evaluate the awareness, attitude and practice of nurses in Mosul's teaching hospital / Iraq about disaster management preparedness. The research sample conducted at Mosul teaching hospital included: (Ibu-Sena Teaching hospital, Al-Jumhoury teaching hospital, General Mosul hospital, Al-khansia teaching hospital and Abu-ather teaching hospital) only, nurses workers in emergency department . In the present analysis a cross- method was applied and Consisting of nurses (76). Data obtained since December 10, 2019 extended to December 30, 2019. This instrument adapted by (Miller,2011; and Moabi,2008). Consists of (4) main sections: section one demographic date e.g: (age, sex, experience, education level, marital status, and hospitals). Section two included: (47) items included: MCQ, True and False, protected information disaster management and preparedness questions with each question listed as correct $(=1)$ and incorrect $(=0)$. Section three consists of eleven elements classified as agree, disagree and unsure for determining the checklist of attitudes about disaster management. Four section practice of regarding disaster management current procedures included concerns about emergency exercises conducted at their healthcare facilities, what types of exercises are undertaken, ongoing preparation, how frequently, updating the emergency plan .The data were analyzed using the SPSS (V:22) and descriptive statistics and inferential statistics (means of score, standard deviation and frequency) between nurses, awareness or knowledge, attitude and practice on disaster management preparedness in Mosul hospital teaching

\section{Results}

Table 1: Frequency distribution of demographic data $(n=76)$ of the emergency nurses.

\begin{tabular}{|l|l|l|}
\hline Nurses Demographic Data & Number & Percentage \\
\hline Age & \multicolumn{2}{|l|}{} \\
\hline $22-32$ Year & 44 & $57.9 \%$ \\
\hline $32-42$ Year & 26 & $34.2 \%$ \\
\hline$>42$ Year & 6 & $7.9 \%$ \\
\hline Mean \pm SD & $28.40 \pm 7.67$ & \\
\hline Gender & \multicolumn{2}{|l|}{} \\
\hline Male & 30 & $39.5 \%$ \\
\hline Female & 46 & $60.5 \%$ \\
\hline Marital status & \multicolumn{2}{|l|}{} \\
\hline Single & 8 & $10.5 \%$ \\
\hline Married & 65 & $85.5 \%$ \\
\hline Widowed & 3 & $4 \%$ \\
\hline Hospital & & \\
\hline
\end{tabular}


Cont... Table 1: Frequency distribution of demographic data $(n=76)$ of the emergency nurses.

\begin{tabular}{|l|l|l|}
\hline General Mosul & 12 & $15.8 \%$ \\
\hline Ibn- Senia & 13 & $17.1 \%$ \\
\hline Al-Khansia & 16 & $21 \%$ \\
\hline Ibn-Atheer & 14 & $18.5 \%$ \\
\hline Al-Jumhoury & 21 & $27.6 \%$ \\
\hline Experience of years & \multicolumn{2}{|l|}{} \\
\hline Less than 5 years & 12 & $15.8 \%$ \\
\hline 5-10years & 29 & $38.2 \%$ \\
\hline$>10 y e a r s$ & 35 & $46 \%$ \\
\hline Mean \pm SD & $8.85 \pm 3.64$ & \multicolumn{2}{|l|}{} \\
\hline Level of education & \multicolumn{2}{|l|}{} \\
\hline Bachelor of nursing & 18 & $23.6 \%$ \\
\hline Diploma of nursing & 49 & $64.5 \%$ \\
\hline Secondary of nursing & 9 & $11.9 \%$ \\
\hline
\end{tabular}

Table 2: Knowledge score regarding disaster among study respondents $(n=76)$

\begin{tabular}{|l|l|l|}
\hline Knowledge of Score (1-47) & Number & Percentage \\
\hline$(1-12)$ & 5 & $6.6 \%$ \\
\hline$(13-24)$ & 51 & $67.1 \%$ \\
\hline$(25-36)$ & 18 & $23.7 \%$ \\
\hline$(37-47)$ & 2 & $2.6 \%$ \\
\hline Mean \pm SD & $22.35 \pm 5.95$ & \\
\hline$t$ value & $(55.82)$ and $\mathrm{P} \leq(.001)($ High Sign $)$ \\
\hline
\end{tabular}

Table (3): Attitude regarding disaster preparedness among the study respondents $(n=76)$

\begin{tabular}{|l|l|l|l|}
\hline Attitude variables & Agree & disagree & Unsure \\
\hline $\begin{array}{l}\text { I don't need to know about operational preparations for an emergency } \\
\text { (disasters) }\end{array}$ & $49(64.5)$ & $21(27.6)$ & $6(7.9)$ \\
\hline Management should be prepared appropriately in the event of a disaster & $55(72.4)$ & $16(21)$ & $5(6.6)$ \\
\hline In the hospital environment, disaster preparation is for everyone. & $40(52.6)$ & $28(36.9)$ & $8(10.5)$ \\
\hline $\begin{array}{l}\text { Potential threats that are likely to cause catastrophe should be identified and } \\
\text { handled. }\end{array}$ & $57(75)$ & $11(14.5)$ & $8(10.5)$ \\
\hline Training is required for all nurses & $62(81.6)$ & $12(15.7)$ & $2(2.7)$ \\
\hline Do you think operational plan for an emergency (disaster) is necessary & $60(79)$ & $13(17.1)$ & $3(3.9)$ \\
\hline Operational emergency (disaster) plan needs to be revised periodically & $54(71)$ & $16(21)$ & $6(8)$ \\
\hline Disasters at our hospital are unlikely to happen & $33(43.5)$ & $29(38.1)$ & $14(18.4)$ \\
\hline Managing the tragedy is not limited to nurses and doctors & $41(54)$ & $25(32.9)$ & $10(13.1)$ \\
\hline Simulations of a catastrophe will always take place in the hospital & $53(69.7)$ & $16(21)$ & $7(9.3)$ \\
\hline Drills will be held in hospital & $59(77.6)$ & $12(15.8)$ & $5(6.6)$ \\
\hline t value 64.289 P $\leq 001$ & & & \\
\hline
\end{tabular}


Table 4: Percentages of the study respondents practice regarding disaster preparedness $(n=76)$

\begin{tabular}{|l|l|l|l|}
\hline Variable & Yes & No & don't know \\
\hline Can you do emergency drills at your hospital? & $49(44.5)$ & $16(21)$ & $11(14.5)$ \\
\hline If so, what kind of drills do they do? & $43(56.5)$ & $21(27.6)$ & $12(15.8)$ \\
\hline Is there ongoing training? & $32(42.1)$ & $28(36.8)$ & $16(21.1)$ \\
\hline Is the disaster plan periodically updated? & $24(31.6)$ & $22(29)$ & $30(39.4)$ \\
\hline $\mathrm{t}$ value $=43.23 \quad$ Sig. P $\leq .001$ High Sign & & & \\
\hline
\end{tabular}

\section{Discussion}

The present study was aimed to investigate nurses' KAP regarding preparedness of disaster management in emergency of Mosul teaching hospitals/Iraq. Table (1): showed that the study respondents were aged between

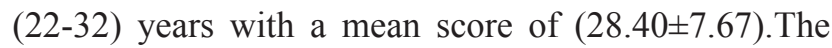
educational standard for approximately (64.5 percent) nursing diploma. There was almost ( 85.5 per cent) married, the present study found that two thirds of emergency nurses were female, this could be attributed to the large number of female nurses who were frequently present during the morning shift, almost (39.5\%) male, female were $(60.5 \%)$ this result was accepted with ${ }^{(1)}$, found the majority of the sample were women. Table (2): show that the level of disaster knowledge fell between two-thirds of the study sample in the group of (13-24) degree of 47 degree with average score of $(22.35 \pm 5.95)$ by very significant differences in value $\mathrm{t}=(55.82)$ and $\mathrm{P} \leq$ (.001). study in Jordanian by (Khalaileh,2012) were investigated of awareness, and preparedness for disaster management.The results suggested that knowledge need to be continually improved in order to change the efficacy for disaster response, and an Integrated emergency Preparedness Program to raising awareness about disaster management. Table 3: shows the percentages of the research participants 'agreement on disaster preparedness attitude that were as follows: $(64.5 \%)$ agreed on the need for awareness of emergency plans, $(72.4 \%)$ appropriate preparation should be prepared in the event of a catastrophe,(52.6\%) emergency readiness should be planned for all people in the hospital environment, $(75 \%)$ possible disaster threats should be recognized and addressed, (81.6\%) preparation is required for all healthcare management, (79\%) emergency planning is important, (71\%) emergency plans should be revised regularly,(43.5\%) accidents are likely to occur in every hospital setting, (54\%) emergency management is for all healthcare teams,

(69.7\%) catastrophe scenarios should be routinely conducted in hospitals and (77.6\%) exercises should be conducted in hospitals. A highly significant difference of attitude was found ( $\mathrm{t}$ value $=64.289$, and $\mathrm{P} \leq .001$ ). Several KAP studies on disaster and emergency preparedness for nurses were performed. A research conducted by Hong Kong nurses found that nurses are not sufficiently trained for disasters, but are mindful of the need for such preparedness. Furthermore, emergency management instruction will be included in nurses basic education ${ }^{(14)}$. Table 4 : reveals that 44.5 percent of the participants in the study were conscious that emergency drills are being performed at their healthcare settings. 21 percent said they weren't done and 14.5 per cent said they didn't. 15.8 percent did not know what kind of drills were done. They reported code blue and fire evacuation of the remaining 56.5 per cent. 42.1 per cent claimed their healthcare facilities had ongoing preparation. 31.6 percent reported that the training was conducted quarterly, 29 percent had not been completed and 39.4 percent had not. There was a highly important difference in the degree of activities as t value $=43.23$ and $\mathrm{P} \leq$.001.This research in Egypt (Khalil, et al., 2019) disagreed with the present report, showing that there was no substantial difference between the activities of nurses regarding disaster preparedness and their demographic characteristics.

\section{Conclusion}

Through the findings of the study concluded that the 
awareness or knowledge of nurses is high with a neutral level of attitude, also practice with respect to disaster preparedness was satisfactory.

\section{Recommendation}

Based on the findings of this report, the researchers suggested that emergency nurses need to incorporate explicitly named theory and practice; teaching disaster and emergency preparedness courses in nursing curricula is important and appropriate in terms of their preferences for training.

Financial Disclosure: There is no financial disclosure.

Conflict of Interest: None to declare.

Ethical Clearance: All experimental protocols were approved under the University of Mosul and all experiments were carried out in accordance with approved guidelines.

\section{References}

1- Nofal A, Alfayyad I, Khan A. Knowledge, attitudes, and practices of emergency department staff towards disaster and emergency preparedness at tertiary health care hospital in central Saudi Arabia. Saudi Medical Journal. 2018; 39(11), 1123-1129.

2- Haddow G, Bullock J, Coppola DP. Introduction to emergency management. Butterworth-Heinemann, $6^{\text {th }}($ Edn. $), 2017: 815$.

3- Ibrahim F. Nurses knowledge, attitudes, practices and familiarity regarding disaster and emergency preparedness-Saudi Arabia. America Journal of Nursing Science. 2014; 3(2): 18-25.

4- Khalil NS, Ahmed SM, Moustafa M. Emergency nurses' Knowledge and Practice Regarding Preparedness of Disaster Management at a University Hospital, Egypt. Nurs Health Care Int J. 2019; 3(3): 000192.

5- Hassmiller S, R Stanley. Public health nursing and the disaster management cycle. Part 4: Issues and approaches in population-centered nursing. 2013;
(23) 10023-STANHOPE-9780323080019

6- Singhal Y, Bhatnagar R, Lal B, Paliwal B. Knowledge, attitudes, and practices of medical internship students regarding disaster preparedness at a tertiary-care hospital of Udaipur, Rajasthan, India. International Journal of Medical Science and Public Health. 2016; 5(8): 1613-1616.

7- Nasir M, Mahmoud M, Ahmed A. Epidemiology Of Deaths From Injuries In Nineveh Governorate (2008_2012) kufa Journal for Nursing sciences. 2014; 4: 232-237.

8- Fatma AA. Nurses Knowledge, Attitudes, Practices and Familiarity Regarding Disaster and Emergency Preparedness - Saudi Arabia. American Journal of Nursing Science. 2014; 3: 18-25.

9- World Health Organization. Emergency preparedness for the health sector and communities - challenges and the way forward. Pre- hospital and disaster Medicine. 2006; 21(Suppl. 4): 97-109.

10- Labrague L, Yboa B. Disaster preparedness in Philippine nurses. Journal of nursing scholarship. 2016; 48(1): 98-105.

11- P. Miller A. An Assessment of emergency department staff knowledge of emergency preparedness. Published thesis Tina Volz, Committee Chair Ruth Hen thorn Committee Member. UMI Copyright 2011by Pro Quest LLC. 2011.

12- RM Moabi. Knowledge, attitudes and practices of health care workers regarding disaster Preparedness At Johannesburg Hospital in Gauteng Province, South Africapublished master thesis of public health. Student No: 9212062N. Inc. 2008.

13- M Al-Khalaileh, E Bond, J A Alasad. Jordanian nurses' perceptions of their preparedness for disaster management. International emergency nursing. 2012; 20(1):14-23.

14- OW Fung, AY Loke, CK Lai. Disaster preparedness among Hong Kong nurses: J Adv Nurs. 2008; 62(6): 698-703. 